\title{
Correction to: Safety or satiety? Spatiotemporal behaviour of a threatened herbivore
}

\author{
Emiliano Mori ${ }^{1}$ (D) Sandro Lovari ${ }^{1,2} \cdot$ Francesca Cozzi $^{1} \cdot$ Chiara Gabbrielli $^{1}$ - Chiara Giari ${ }^{1} \cdot$ Letizia Torniai $^{1}$. \\ Giorgia Romeo $^{3}$. Francesco Ferretti ${ }^{1} \cdot$ Niccolò Fattorini $^{1}$ (i)
}

Published online: 25 January 2021

(c) Deutsche Gesellschaft für Säugetierkunde 2021

\section{Correction to: Mammalian Biology (2020) 100:49-61 https://doi.org/10.1007/s42991-020-00013-1}

The original version of this article unfortunately contained two mistakes. Firstly, the caption of Fig. 4 was incorrect. The corrected figure caption is given below. Secondly, the electronic supplementary material has been exchanged because Table S1 was incorrectly named Table S2. Only one figure and one table have been kept in the Supplemental material (Figure S1). The original article and the supplemental file have been corrected.

The original article can be found online at https://doi.org/10.1007/ s42991-020-00013-1.

Electronic supplementary material The online version of this article (https://doi.org/10.1007/s42991-020-00095-x) contains supplementary material, which is available to authorized users.

Emiliano Mori

moriemiliano@tiscali.it

1 Department of Life Sciences, University of Siena, Via P.A. Mattioli, 4, 53100 Siena, Italy

2 Maremma Natural History Museum, Strada Corsini, 5, 58100 Grosseto, Italy

3 Wildlife Section, Tuscan Regional Council, Via Trieste, 5, 58100 Grosseto, Italy 
(a) $\quad \begin{aligned} & \text { Cold period } \\ & N=1646 \text { fixes }\end{aligned}$

Warm period

$N=1687$ fixes

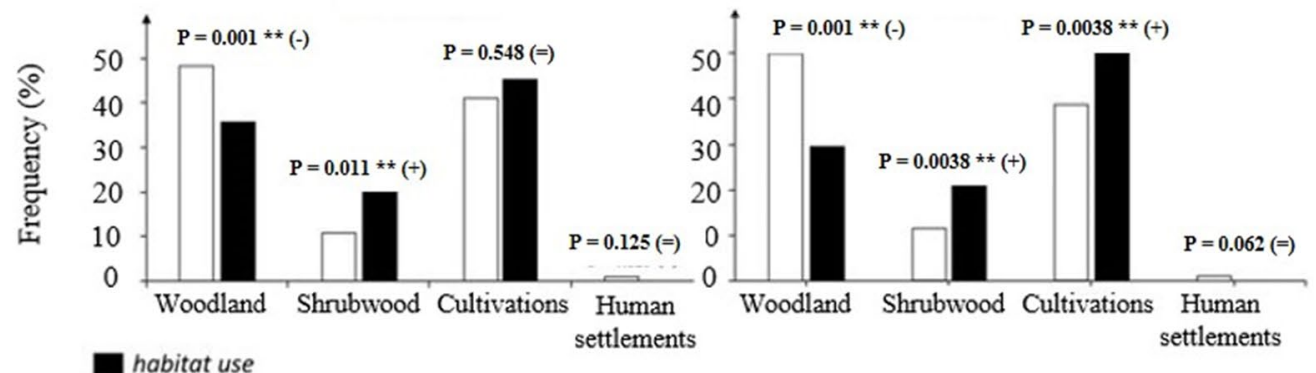

habitat use

$\square$ habitat availability

(b)
Cold period

$N=841$ fixes
Warm period

$N=860$ fixes
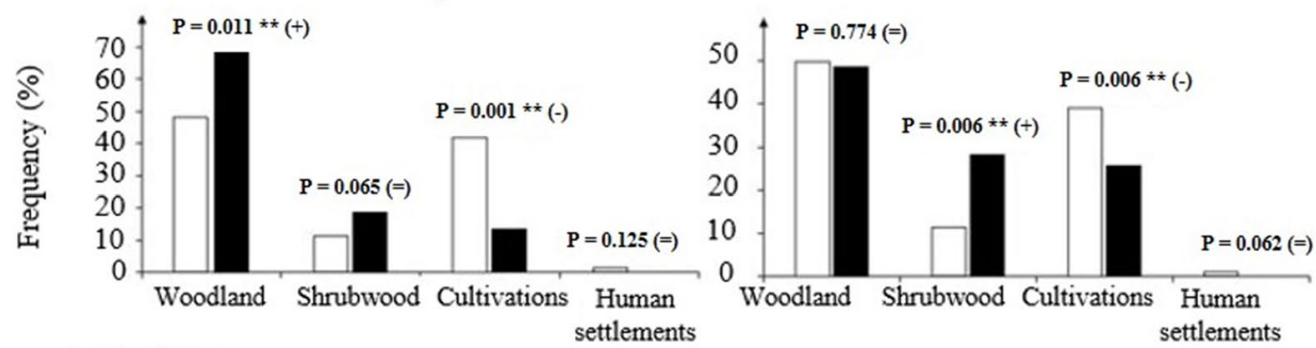

habitat use

habitat availability (c)

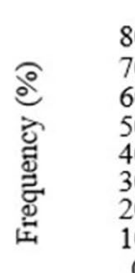

Cold period

$N=805$ fixes

\section{Warm period}

$N=827$ fixes

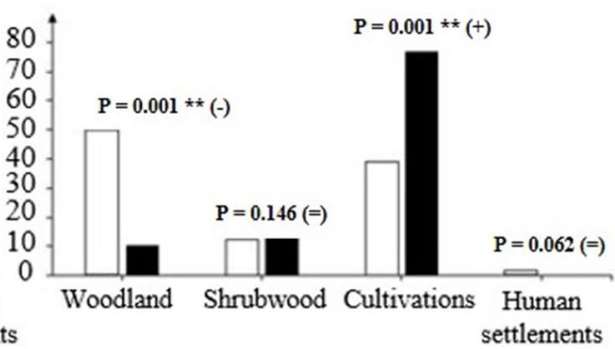

\section{$24 \mathrm{~h}$}
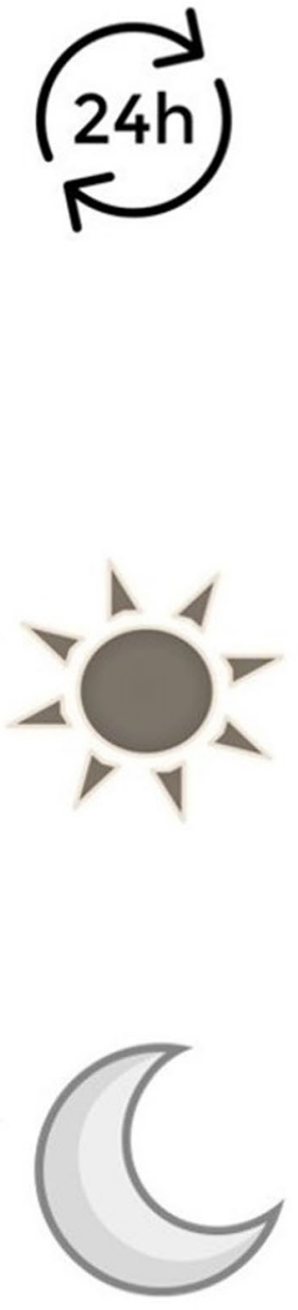

Fig. 4 Habitat selection within home ranges in the cold (left) and in the warm (right) period, a during the 24-h cycle, b during the light, and $\mathbf{c}$ during the night. Asterisks indicate significant $(*)$ and highly significant $(* *) P$ values. The $y$-axis shows frequency of fixes

Publisher's Note Springer Nature remains neutral with regard to jurisdictional claims in published maps and institutional affiliations. 